\title{
Research on Evaluation Index System of Rotating Classroom Teaching Model for College English
}

\author{
Xueqin Li \\ Teaching and Research Institute of Foreign Languages, Bohai University, Jinzhou, 121013, China \\ 284554744@qq.com
}

Keywords: college English; rotating classroom; teaching model; evaluation index system

\begin{abstract}
Rotating classroom teaching mode is to re-adjust the time inside and outside the classroom, transferred the decision of learning from teachers to students, teachers through assistance and communication to help students learn. This paper aims to promote the reform of college English teaching model. According to the rotating classroom teaching process model, and according to the principle of evaluation index system designed evaluation index system model consisted of six first grade indexes such as "teaching resources, teaching design, ability training, teacher teaching, teaching process, student learning" and the six secondary indicators under each first grade indexes, and briefly described the index system. The research results of this paper play an important role in improving the effect of English teaching and cultivating students' autonomous learning ability.
\end{abstract}

\section{Introduction}

Teaching model is a more stable structure of the framework of teaching activities and activities procedures established under the guidance of certain teaching ideas or teaching theory. As a structural framework, it highlights the teaching model from the macro to grasp the teaching activities as a whole and the internal relationship between the elements; as a program of activities, it highlights the order of teaching and operability. The development trend of modern teaching mode is: from a single teaching mode to diversified development; the introduction of non-cognitive psychological factors into classroom teaching; emphasis on students in the teaching of the dominant position; increased feedback and the formation of links; in research methods, From the induction to the development of deductive law; attention to the development and application of modern educational technology, a substantial increase in teaching effectiveness; in the use of the model, emphasizing flexible and flexible.

Rotating classroom teaching mode to reorient the allocation of time inside and outside the classroom, transfer the decision of learning from the teacher to the student, the core of the study is the student; the teacher becomes the student to learn the designer, the instructor, the helper and the learning partner. Rotating classroom teaching mode is to flip the classroom teaching mode development and innovation, in line with the principle of individualized teaching. At the same time, the autonomy of the classroom to the students, teachers only through assistance and communication to assist students to learn, students according to their own needs, free to establish their own knowledge system.

From the nature of language and the law of learning, language is the product of social needs and practice. Language only in the communication of vitality, in the use of language can really learn the language. Therefore, foreign language teaching should be the language as a tool to the students, in the process of communication to truly understand the purpose of language learning, experience the practical value of language. The use of rotating classroom teaching mode, the teaching of knowledge referred to before the class, teachers and students in the classroom have time to discuss, so as to increase the students use the language of the opportunity to promote students to language knowledge and internal control.

Teaching evaluation is based on the teaching objectives of the teaching process and the results of 
the value of judgment and teaching decision-making services, is the reality of teaching activities or the potential value of the process of making judgments. Teaching evaluation generally includes the evaluation of teachers, students, teaching contents, teaching methods, teaching environment and teaching management in the teaching process. Teaching evaluation is an indispensable part of teaching activities, in the teaching process to play a multi-faceted role, from the overall adjustment and control of teaching activities to ensure that teaching activities to achieve the intended goal. Specifically, the teaching evaluation has the effect of checking and teaching, diagnosing teaching problems, providing feedback information, guiding teaching direction and regulating teaching process.

Using a single indicator or a few indicators has a certain one-sidedness and subjectivity. The development of scientific, systematic and comprehensive evaluation index system is the basic work of systematic evaluation. System refers to a certain range or similar things in accordance with a certain order and internal links from the whole, only scientific and reasonable evaluation of the index system; it is possible to come to the scientific and impartial evaluation conclusions. This paper aims at improving the college English teaching and improving the teaching effect of college English teaching for the evaluation of college English rotating classroom teaching mode.

\section{Teaching Process Model of Rotating Classroom}

The teaching process is the start of the teaching activities, development, change and the end of the program structure in time. In the teaching process, teachers have planned to guide students to carry out awareness activities, adjust students 'interest and emotion, step by step to master the cultural and scientific knowledge and basic skills to promote students' intellectual, physical and social character, aesthetic taste development, and Students lay the foundation of a scientific world view. In the teaching process, students, teachers, teaching content, teaching methods, teaching media and teaching environment, is the basic factors that affect the teaching effect, but on the whole, teachers, students and teaching content is the teaching process of the three elements. Rotating classroom teaching process, including pre-class knowledge transfer, class and internalization expansion and after-school evaluation to improve the three main links, teaching process model is shown in Fig. 1.

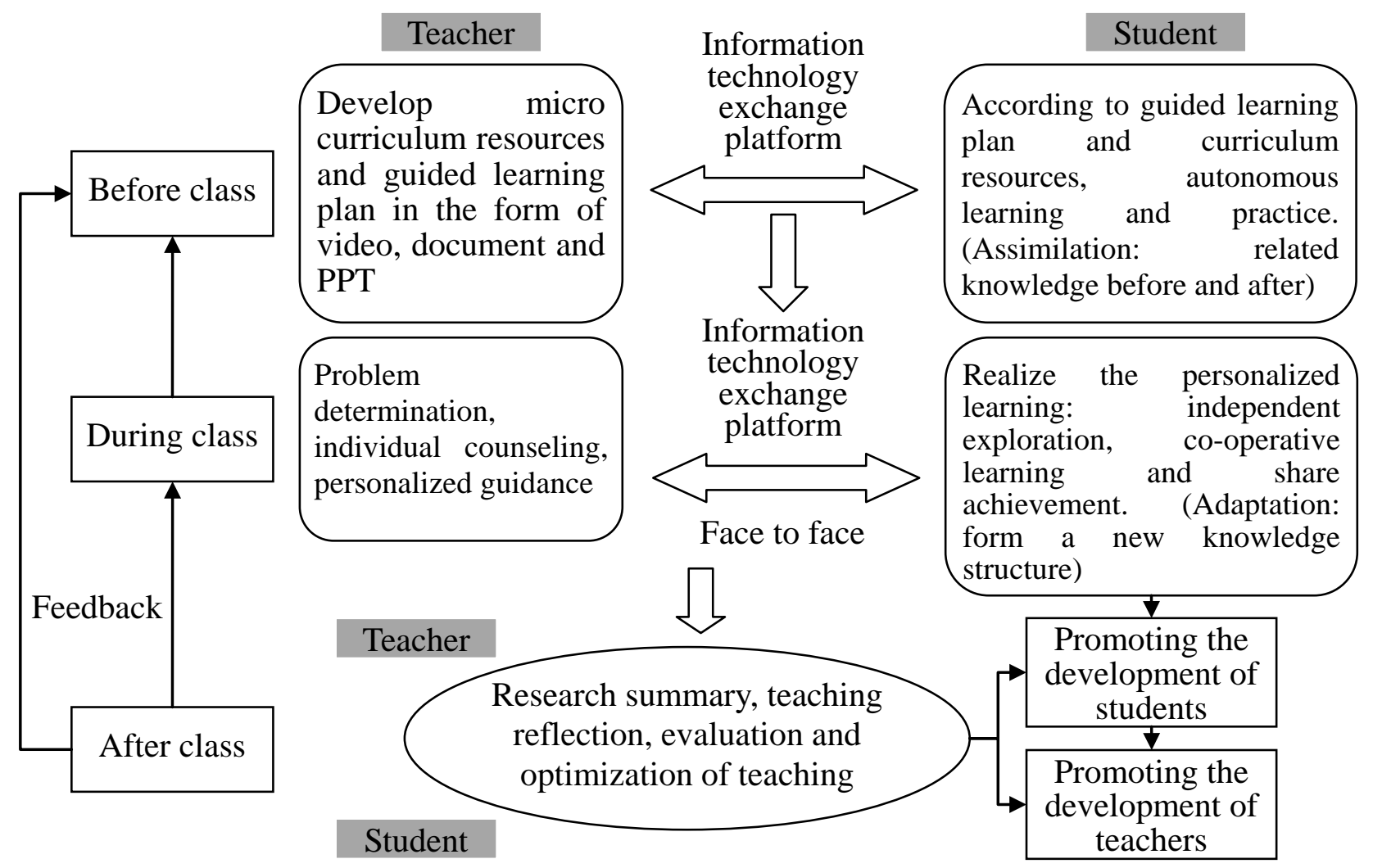

Fig. 1. Teaching process design on "Flipped classroom" 
(1) Pre-class: knowledge transfer. Rotating classroom teaching mode, the basic knowledge on pre-class study, before the students have mastered the basic knowledge, class is no longer repeated. Pre-class tasks is to focus on the basic concepts and basic definitions, the teaching focus and difficult to put forward, to inspire students to solve the problem of thinking. Grasp the teaching focus, difficulty and other knowledge points at the same time, to cultivate students to learn by analogy. Pre-school learning needs to support the learning resources, supporting learning resources for the micro-video-based, to create a real English situation for students, through the situation of inquiry and processing to achieve learning objectives.

(2) Class: internalization expansion. Rotating classroom releases the classroom time for the internalization of the student's knowledge by transferring the knowledge to the pre-class. In the class, teachers spend less time, follow the strategy of "learning from school, teaching and learning" and "teaching with what" to focus on the students' attention, explaining the key points, difficulties and key points so that students can subject knowledge points are fully understood. To carry out collaborative inquiry teaching, under the guidance of teachers, so that students take the initiative to explore the group to master and understand the problem and find ways to find things the cause and internal links, from which to find the law, the formation of their own concepts.

(3) After class: evaluation improvement. The team reports on learning outcomes and communicates and shares with other groups. So that students systematic and structured the content of self-study and classroom explore learning, teachers help students to sort out the knowledge, summed up the knowledge framework, problem-solving methods and techniques. "Rotating classroom" not only focus on the evaluation of the learning effect, but also focus on the evaluation of the learning process, truly quantitative and qualitative evaluation, formative evaluation and summary evaluation, evaluation of the individual and evaluation of the group, self-evaluation and Others evaluate the good combination between.

\section{Establishment Principles of Evaluation Index System}

The principles of evaluation are the principles, guidelines and requirements that must be followed in the evaluation activities. Only clear the principle of evaluation, in order to ensure the normalization and scientific evaluation of the work. According to the understanding of the nature of the evaluation of the nature of the characteristics of college English teaching, with reference to other relevant references, the construction of evaluation index system should follow the following principles:

(1) The principle of combining of advanced concepts and realistic conditions. The indicators of the evaluation system should clearly reflect the ideas, concepts and principles of rotating the classroom teaching mode, and reflect the new requirements of autonomous learning activities and college English teaching. The advanced nature of the evaluation index should be realistic and objective. Indicators are set too high, difficult to achieve, can not be understood by most teachers, will lose the incentive effect; indicators set too low, they will lose the advanced nature of indicators and guidance, teaching does not have a role in promoting.

(2) The principle of combining of common standards and characteristics points. The evaluation indicators of the majority of teachers are universal, for the rotation of classroom teaching model evaluation has a common standard. However, teaching is a complex and changing process, the teacher's personality and expertise is also different, the evaluation system should be teachers to form their own style to leave space, not because of uniform requirements and stifle personality and characteristics of the characteristics of teachers teaching to give the characteristics of extra points, affirm and encourage the characteristics of teaching.

(3) The principle of combining of simplicity and guidance. Teaching evaluation is a very practical work, the composition of the evaluation system has a strong practicality. Indicators should be simple, easy to master and use. Open, fair and practical evaluation system is not only the basis for the evaluation of teaching, but also constantly change the teaching ideas, improve teaching methods and improve the quality of classroom teaching a direct reference. However, too simple 
index system may be easy to master and operate, but it is not conducive to the teaching of the guidance.

(4) The principle of combining of comprehensive evaluation and key evaluation. Teaching evaluation has its own laws, there are recognized standards. A comprehensive collection of information and participate in the evaluation, is to ensure that the evaluation of scientific and objective criteria. But the comprehensive evaluation is not exhaustive, but should refer to the evaluation criteria, in view of the characteristics of college English teaching, to meet the comprehensive information and objective science on the basis of the system, highlighting the advanced nature of the evaluation system and advocacy, appropriate selection of evaluation indicators and distribution weights.

\section{Structure Model of Evaluation Index System}

The process of the evaluation index system is summarizing and sorting the collected data, breaking down the practical problems into several factors, dividing the factors into groups according to different attributes. The hierarchical structure can be divided into the highest level, the middle layer and the bottom The upper layer, also known as the top layer or target layer, has only one element, indicating the purpose of the system or the overall goal; the middle layer, also known as the criterion layer, that the realization of the overall goal of the system involved in the intermediate links, according to the size and complexity of the size of the problem There are multiple layers; the bottom layer, also known as the program layer or measures layer, said to achieve the goal to be selected by the various measures, decisions, programs and so on. According to the process model of rotating the classroom teaching process, six primary indicators, namely, teaching resources, teaching design, ability training, teacher teaching, student learning and teaching process, are designed. Each level index includes six evaluation indexes of secondary indicators system. The evaluation index system represented by the hierarchical analysis model is shown in Fig. 2. 


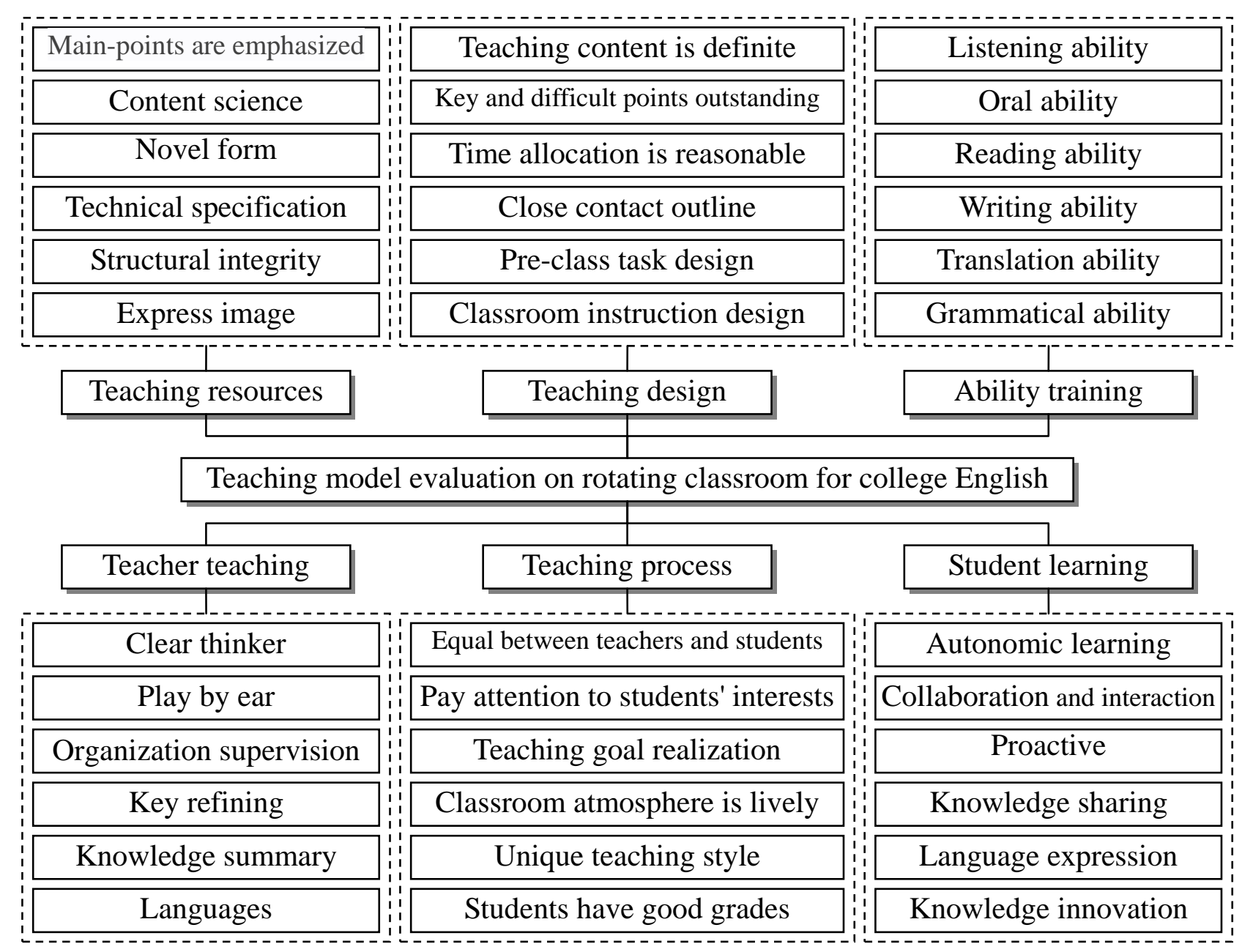

Fig. 2. Structure model on evaluation index system of rotating classroom teaching model for college English

\section{Brief Description of Evaluation Index System}

The first grade index of the evaluation index architecture model shown in Fig. 2 is briefly described as follows:

(1) Teaching resources. Teaching resources are materials that can be used for the effective development of teaching materials, including teaching materials, cases, films, pictures and courseware. This article mainly refers to the rotation of the classroom teaching students for pre-class learning resources.

(2) Teaching design. According to the requirements of the curriculum standards and the characteristics of teaching objects, the elements of teaching arrangements in order to determine the appropriate teaching program ideas and plans. Generally includes teaching objectives, teaching difficult, teaching methods, teaching steps and time allocation and other links.

(3) Capacity training. College English is based on the theory of foreign language teaching, with English language knowledge and application skills, cross-cultural communication and learning strategies as the main content, mainly to develop students' English comprehensive application ability, including listening, speaking, reading, writing, translation and grammar And so on.

(4) Teacher teaching. Rotating classroom teaching evaluation, including pre-class, class and after class and other links, but the core is fine talk links. Fine talk is to Rotating classroom teaching mode in the key link, plays a guiding role, is the students to form a new cognitive structure of the key process.

(5) Student learning. Rotating classroom emphasize student-centered and autonomous learning, students in the teaching resources under the support of pre-class basic knowledge and basic 
concepts to complete the study, the group to learn and communicate with each other, after the completion of knowledge consolidation, focusing on students' positive Sex.

(6) Teaching process. Teachers according to certain social requirements and the characteristics of physical and mental development of students, with certain teaching conditions guide students through the understanding of teaching content to understand the objective world, and on the basis of the development of their own process.

\section{References}

[1] Z. C. Zhang, "College English classroom teaching strategies in the context of classroom rotation," Journal of Bohai University(Philosophy \& Social Science Edition), vol. 38, no. 3, pp. 139-140, 2016.

[2] B. Q. Liu, "Technical characteristics and development trend of the flipped classroom," The Chinese Journal of ICT in Education, vol. 21, no. 18, pp. 11-15, 2015.

[3] X. M. Liu, "Construction of College English classroom teaching evaluation system in the era of big data," Modern Educational Technology, vol. 26, no. 1, pp. 94-99, 2016.

[4] Education Department of Liaoning Province, "The reform of classroom teaching mode in Bohai University: turning the classroom," http://www.lnen.cn/jyzx/yxxw/283452.shtml, 2017-5-20.

[5] Z. X. Liu, Q. H. Wu, "The cultivation of college students' autonomous learning ability from the perspective of flipped classroom," Modern educational technology, vol. 25, no. 11, pp. 67-72, 2015.

[6] C. L. Tai, S. J. Shi, D. Pang, et al., "The initial construction of the evaluation index system of flipped classroom teaching," Chinese Journal of Nursing Education, vol. 14, no. 1, pp. 18-22, 2017. 